\title{
Research Based on Multi-modal Perspective College Oral English Class Model*
}

\author{
Yi Liu \\ Anhui Sanlian University \\ Hefei, China 230601
}

\begin{abstract}
This paper discusses the Multimodal Discourse Theory in College English Class. Multimodal Discourse Theory is based on the current college English teaching methods and strategies to integrate multi-modal Construction of Oral English Classroom Teaching Model. Study Multimodal Approach and College English Teaching in a combination of discovery: the teaching model can effectively improve the effect of college English classroom teaching to promote independent learning enthusiasm, the majority of foreign language teachers teaching and research have a certain inspiration.
\end{abstract}

Keywords-Multi-modal perspective; Oral English; Mode

\section{INTRODUCTION}

With the development of university graduates speaking ability universal attention of employers, but many college students after years of English learning, still unable to speak fluent English. Survey shows that employers in recent years College English comprehensive ability unhappy, they think that only a small number of college students with strong English skills, most of the students' oral ability is poor or very poor. The reason for this condition is very complex, but the university English teaching in malpractice is one of the important factors that affect students' oral communicative competence. Since the multimedia technology into the classroom, foreign language teaching activities also gradually showing digital and multi-modal technology characteristics, which provides the possibility to advance college English teaching, to build a multi-modal model of spoken classroom.

Modal means to achieve symbolic resources of verbal communication, it can be one or more medium to achieve. We feel outside of visual, auditory, tactile feel is modal, and feel the aid of tools, eyes, ears, hands is the media. When multi-modal communication is used for a variety of modes, such as language, color, taste, image and so on. Multimodal Discourse is that people use auditory, visual, tactile and other sensory, language, images, sounds, movement and other symbolic resources as a medium for communication phenomena ${ }^{[1]}$.

Multimodal discourse analysis theory emerged in the 1990 s as a relatively independent of the cutting-edge

*Fund Project: This paper is the research result that focused on humanities and social sciences key project of Anhui Provincial Education Department "A Comparative Study of Faulkner and Mo Yan works of modern and post-modern Theory of overall under" (Item Number: SK2014A245). academic research, Multimodal discourse analysis mainly refers to the use of a variety of means people in the communication process, such as language, sounds, image, movement, etc. to communicate and obtain information on the phenomenon. In Western academia, the first Multi-modal discourse analysis theory is R. Barthes, he published "Images of rhetoric" (Rhetoric of the Image) in 1977, explores the interaction between language and image in the sense of the expression, creating a multi-modal discourse analysis precedent. True multi-modal discourse analysis and language teaching of combining study is New London Group (New London Group, 1996), they point out, in language teaching, teachers should consciously to student input information through a variety of teaching methods, gradually students Multiliteracies (Multiliteracy), thus completing the main task of language teaching and to achieve the ideal of teaching effectiveness.

Multimodal Discourse Analysis in Teaching has become a hot topic in the West focus on academia, but the domestic research involved in this field is still in its infancy. China began to attach importance to the study of multi-modal discourse from the beginning of the 21st century, Hu Zhuang Lin, Zhu Yongsheng Mood and Modality each were studied from a theoretical and practical perspective. Mood and Modality think: Theoretical Foundations Multimodal discourse analysis is the system function linguistics theory, which includes five levels: the cultural level, including as a main form of culture, ideology and discourse as a mode selection Generic Structure Potential; language border level, including by the discourse context configuration range, tenor and mode of discourse consisting of; significance level, including the significance of discourse consists of several components, namely, the concept of meaning, interpersonal meaning and rules and meaning; formal level and achieve meaningful different forms of the system, including the relationship between language, vocabulary grammar system and various other modes of ideographic form, grammatical system and a variety of modes between grammar; medium level of discourse is the ultimate manifestation in the physical world, including language and nonverbal two categories. ${ }^{[2]}$ Multimodal Discourse analysis of discourse to break the traditional language of symbols formed based analysis of the situation, focusing on auditory, visual, tactile, and other symbols to complete common sense representation form, and the media in the form of extended language levels scope of the study to learn. 
However, the current domestic research on spoken English teaching will be applied to multi-modal teaching methods, have not formed a systematic theories and models, on the basis of the results of previous studies on the absorption, to explore in a multi-modal perspective, how to use the interaction of various modes to build a new type of university English classroom model.

\section{College Oral English Teaching Problems}

The current college English classroom teaching time is limited, and most of the time was occupied by teachers to explain students passive acceptance of knowledge, lack of opportunity for oral expression, boring classroom atmosphere, many students considered dispensable oral class, often absent. Mainly from the teachers, students, teaching environmental aspects to analyze the resulting current university teaching poorly performing oral reasons.

\section{A. Teachers Teaching Model Can not Meet the Needs of Students}

"Chinese students speaking practice, mainly through the acquisition of classroom teaching, classroom teachers in the teaching of language knowledge is only declarative knowledge only through specific real communication activities, to get some kind of consciousness, this knowledge can be automatically converted to the language skills, pure explain to gain practical knowledge of basic communicative competence will not achieve a critical role. ${ }^{[3]}$ However, in the current oral classroom teacher is still dominant, language input students rely mainly on teacher talk this single modality, teachers blindly ground chalk and talk, the students really left little time, can not meet the needs of a large number of student output.

Although information technology has been applied in a number of foreign language teaching, but most of the teachers in the spoken language class still follow traditional teaching methods and models. For example, in college English classroom, many teachers prefer the use of multimedia courseware to assist in teaching, but the design of the multimedia courseware, teachers in the use of modal relatively simple, and did not play the full range of students to mobilize a variety of senses the root causes of action, causing such problems is that teachers did not use newer and more effective teaching methods and teaching mode based on multimedia features. ${ }^{[4]}$

\section{B. Low Student Self-efficacy in Learning Spoken Language}

"According to Bandura's theory of motivation, selfefficacy refers to individuals whether they can successfully carry out an act of subjective judgment ability, which affects the behavior of individual choice, how hard and how long." [5]

When Chinese college students currently performing spoken generally not confident in the classroom ashamed to speak, he refused to take the initiative to speak, but do not want to communicate with foreigners. The more afraid to speak would not say more, more will not say more is not open, forming a vicious cycle. Thus, the students' self- efficacy is low, there is a certain negative impact on verbal learning.

\section{Foreign Language Teaching Environment Is not Perfect}

Practice has proved that oral teaching in the creation of the real situation, to learn better. In the current teaching practice oral English universities, usually can not be real communication situation directly to the learner, which requires the use of modern information technology to render Multimodality teaching situation. Good multi-modal environment needs to support foreign language teaching scene, teaching aids, the media and other conditions, but the current foreign language teaching environment, many universities are still not perfect, which directly affect the actual effect of oral teaching. The lack of hardware facilities to some extent hindered and restricted the college English classroom to the multi-modal direction.

\section{BUILD A MULTI-MODAL SPOKEN ENGLISH ClassROOM TEACHING MODEL}

In this paper, a freshman spoken as the main object of study, research done by the predecessors of multimodal discourse in the classroom teaching, to explore how to multimodal discourse analysis applied to spoken language teaching freshman class, the rich conversation class teaching contents and expressions.

\section{A. The Idea of Curriculum Design}

Courses to improve students' oral as a fundamental objective in training students spoken simultaneously, to enable students to understand Western culture as the basic goal. At the same time, should be based on multi-modal classroom presentation, better use of video, classroom arrangement, combined with teacher ppt language media should also be greater use of classroom scenario simulation mode, in order to enrich the classroom forms, make students better understand what they learn, to improve students' listening and speaking ability.

\section{B. The Content of the Curriculum Design}

The course design is mainly based on the cultural level, including the Chinese culture and Western culture, each class with a topic as the theme to start learning. Difficulty and depth of content with the passage of time and the accumulation of knowledge continue to increase and deepen. For example, first semester may consist of the following topics: the "new friends" "around my new school," "understanding of American geography," "Food," "travel," "People," "Holiday," "art." As previously mentioned, in the initial stage of the course, the difficulty of the course content should not be too large, mainly in order to stimulate students' interest and promote their understanding of classroom-type, in order to stimulate their participation in classroom activities. Because the most important goal is to encourage students to dare to oral class to express in English, learn how to express, therefore, active participation of students is especially important. Thereafter, as the course schedule, you can gradually increase the difficulty of the content. In each a 
big topic, it can be divided into different small topics taught. As in "festival" in this topic, you can specifically explain important festival in Western countries, and to celebrate their form, allowing students to better understand Western culture, develop their understanding of contextual knowledge.

\section{The Method of Classroom Presentation}

Oral class to develop students' communicative competence as the main purpose, therefore, is relatively active classroom atmosphere, classroom forms should also be flexible, should be "performance-based student teachers presented teaching supplement" for the purpose. ${ }^{[6]}$ In the multi-modal discourse analysis under the guidance of the theory, conversation classes should not be based on traditional resource-based textbooks, teacher, "said" or students, "said" the main, but teachers should pay attention to the rational use of language media and combine nonlinguistic media, in particular non-language media, use the "tools" such as classroom arrangement, multimedia technology such as the use and teaching of locations should also be flexible, you can select a location beyond the classroom, as long as lectures were easy.

Course content into link - in audio, video, image as the main teaching methods, with text descriptions ppt auxiliary. And the content of ppt, to highlight the key elements, such as changing the font and color, causing the students' attention visually. Similarly, the "Festival of Christmas" for example, teachers must first be able to show students some Christmasrelated images, such as Christmas trees, Santa Claus, blessing cards, etc., then you can play Christmas carols or Christmas cartoons, etc., while accompanied by the text of the content of this lesson ppt show to students for Christmas.

Course content impressions link - This link is the core part of the whole class, the teacher to explain - language media as the main teaching methods, accompanied by text ppt auxiliary teaching methods, the same design should pay attention to ppt, through some animation effects ppt to increase the vividness. In addition, in this session, teachers should pay attention to and make full use of the classroom surroundings. As in the "Christmas" as the topic of teaching, teachers can enter ppt in the origins of Christmas, it's time to celebrate and celebration, so that when the explanation will become more intuitive, more hierarchical. Then, the teacher can choose to schedule this lesson in the Christmas is approaching, so the surrounding environment for the students to provide favorable conditions. For example, teachers and students can be arranged together with the classroom, with students then decorate the Christmas tree, throw a party, and students together to celebrate Christmas in these operations, for the students on Christmas. Such nonverbal language media and media together, not only enriches the classroom in the form, but also convenient for students to better learn the content taught.

Classroom interactive sessions - the link is the most important part inferior classroom content presented in the media as the main language of teaching methods, ppt, audio and video for the aid. In this session, students in a dominant position, just by the language teacher told the students what tasks need to be discussed. Students in small groups, discuss and exchange to complete the tasks assigned by the teacher, taking full advantage of the props, so that their performance more intuitive. As "food" of the topic, the students can explain the process, the physical display to the audience, if not physical, it can be related to the picture show you.

In conversation classes, the language media although very important, but they can not ignore the use of nonlanguage media, the relationship between the media in the form of a complementary relationship between different aspects of the use of different media to make education better. [7]

\section{MULTI-MODAL ANALYSIS IMPLICATIONS TO College ENGLish ClassRoOM TEACHING}

\section{A. Change the Role of Teachers: From the Master's to Designer}

Construction of multi-modal college English classroom mode change means that the role of teachers. Teachers 'Role Transition from the host to designers who need to set up relevant courses to strengthen the capacity of the theoretical teaching literacy teachers and multi-modal reading and writing,${ }^{[8]}$ while schools can also organize teaching demonstration, lectures and seminars to promote the teachers' sharing of information between the resources, improve teachers' ability to respond. Teachers will no longer be limited to a single mode in the past, by the master of all teachers teaching mode, but active use of multi-modal teaching methods, the integration of a variety of audio, network resources and educational software, to achieve the optimal combination of various modalities, designed maps, text, sound, shape into one oral class, all-round, multi-level to stimulate students so that they perceive language materials from various sources. At the same time, teachers should adhere to the principle of optimal allocation of resources to meet students' individual needs, so that students can master the effective communication principle, a deep understanding of the intrinsic link between linguistic form and linguistic connotation, so as to improve oral communication skills.

\section{B. Changing Student Roles: From Passive to Active Participation in the Creation}

Multimodality College English classroom model, students from the past passive participants become active creators. Teachers can create a competitive atmosphere in the classroom to mobilize the enthusiasm of the students, such as taking group competition system, individual incentives. At the same time, teachers should change the past, a single evaluation methods, develop evaluation table record student performance in the classroom, as usually results included in the final examination. Modern multimedia technology in different forms will be rich, authentic language material presented in front of students, they need to mobilize a variety of senses to absorb. A variety of activities in the classroom, students need to go and participate in the classroom students to become "hero", they must give full play to the imagination and initiative to complete one full of fun, challenging task, to create a classroom flash point. 


\section{Teaching Activities}

1) Create a real context, the desire to stimulate communication.

Spoken language teaching should form, content and language Communication in three plates fused into a whole. Students in oral practice to try to do with substance, to avoid voids content of the speech, irrelevance. Oral contrast to traditional classroom mainly depends on teachers on the single mode, in multi-modal learning environment, teachers can use topic-related pictures and even kind to stimulate students' awareness of the senses, a three-dimensional, threedimensional way student information enter. For example, on a motion to the topic of oral lessons, teachers can first show students accompanied by a series of picture and explain. Students have a certain knowledge and vocabulary after asking them to think of myself as a president of the Athletic Association, the need to design a poster to recruit new members for their association and in accordance with the content of the poster compiled some attractive Naxin declaration. After the student is ready, you can turn on stage, and finally to a maximum number of members to recruit students will be rewarded. Classroom teachers will be teaching content oral contact with the reality of living together, help students migrate reality Communicative rule in the classes.

Only the language skills and knowledge into the true nature of the language environment, learners can take the initiative to master the language. ${ }^{[9]}$ Students enrolled in the early adoption of the new communities have experienced, so in the face of this topic prone to intimacy, to master new forms of oral communication strategies in classroom activities. The teacher asks the students how to make a poster, using the tactile modality for students to create the realism of communication to help them eliminate tension, slack mood, conduct combat training in a relaxed atmosphere in the classroom, to stimulate students' desire for communication, and effectively improve their spoken English ability.

2) With film and television media, divergent thinking of students.

Film and television as a carrier is more common teaching methods, it mainly refers to the teacher by means of visual material in audio and video materials assisted teaching, strengthen students' language input. Teachers selected video material can either be the original film, it may also be a news video, or taken from a program fragment. The film applied to teaching English in the classroom is not a simple film appreciation, generally before the official watch student teachers give students arranged corresponding tasks, such as requiring students to guess the identity of the video characters, circumstances surrounding the incident. The entire teaching process is the task of teachers in each arrangement gradually advancing.

Teachers can allow students to watch for some 15 minutes or so, no subtitles, no sound of a video clip (video clip taken from a unit of relatively old age of niche films, students not previously seen), then the students will appear in accordance with the movie role the number is divided into several groups, asking them to play to their imagination to movie clips roles lines coupled with content, live performances improvised dubbing. Students assigned roles based on the results of group discussions, each a 10-minute preparation time after the turn ready to perform on stage. After all the groups performing, playing the original video content by teachers to compare. Students rich imagination help create a lively classroom atmosphere, to achieve good teaching results.

In this case, the teacher designed "film dubbing" to enable students to interact through visual and video, then according to their ingenious idea to design a reasonable plot. Relaxed, pleasant learning environment to stimulate student initiative and interest in learning, improve self-efficacy are virtually becomes less difficult to express in English.

3) To Make the Best Use Pictures or Objects, Auxiliary Spoken.

In designing an in scenic as the topic of oral lessons, teachers can first before class requires students to collect a large hometown, alma mater of the picture or video and made the courseware, and then during the final class, put some interception from English tour program video, the content can be introduced for some famous sights. Teachers help students summarize the video typical sentence tourismrelated and high-frequency vocabulary, oral practice for students to use in the subsequent reference; then arranged teacher gives students a task: as a tour guide. Students can combine the prepared courseware, to introduce English alma mater or hometown scenery. In this case, teachers encourage students to apply what they have learned to others introduce hometown or alma mater of scenery will help stimulate students empathy, to understand the English-speaking fun. In the course of the activity, the teacher in charge of student videos and pick and choose some of the better videos and students reviews watch together. Students learn by means of pictures, photos and other tools to aid their oral expression, the use of multi-modal coordination between social communication can effectively restore true colors, its multimodal information processing capacity has virtually been improved.

\section{4) Coordination of Various Modes of Cultural Connotation Penetration. \\ Culture rooted in language, multi-modal teaching methods to be effective in culture and language learning together. Oral English Class common forms of activities --- drama performances, for example, students can rehearse the drama, the emotional experience of the characters, and then act out in their own way, both to practice spoken language students, but also test them expressiveness and appeal, can effectively cultural awareness and into the spoken language practice. To adopt a form of drama performances oral class, for example, teachers provide students with "Hamlet" in English script, the students spontaneously formed several small crew, according to team members to discuss arrangements for performing fragment and dispatch roles.}

There are three official in class groups were performing the script in three different clips. The students in order to better restore the original script, use background music to set the mood; some students in order to make the performance 
come alive, trying to imitate the characters in the script behavior habits unspeakable conversation; more specifically a group dressed as the characters It looks like. Teachers did not intervene in the whole class of students in the show, has been acting as the audience, only after the end of the show, highlights or defect for each put forward their views and discuss with students.

Student drama performances, dynamic resource clothing, hairstyles, props and other static resources and voice, facial expressions, movements, etc. are included in the process of spoken language practice, "The real language environment can help them get rid of the fetters up mode of thinking, to mobilize the senses brain and language information while viewing modes melt comprehensive response, naturally absorb the language. "while incorporating visual modality, to students all-round, multi-sensory experience, can better communicate in the language of cultural connotation to students develop their multi-modal verbal communication skills.

\section{CONCLUSION}

The information age has accelerated the pace of college English teaching reform, the most important thing is the support and promotion of the new English teaching mode multi-modal College English Teaching. In this paper, multimodal discourse analysis theory as a framework to explore the college spoken English teaching mode multimodal context. Studies have shown that the new college English classroom teaching mode, multi-modal context effective use of modern educational information technology, classroom teaching by the transition to a multi-modal singlemode, improve student participation in class, at the same time forward also changed the attitude of students, promote their self-learning ability, the entire teaching effectiveness spoken English class has been significantly improved.

Despite multimodal teaching model for college English teaching reform to provide strong technical support, but the role played by teachers still can not be ignored. Throughout the multi-modal teaching process, teachers not only builders and implementers classroom model, but also multi-modal student independent study director, therefore, college English teachers in the teaching practice to the times, to promote the development of new college English teaching mode.

\section{REFERENCES}

[1] Kress,G.R. \& Leeuwen, T.Van. Multimodal Discourse: The Modes and Media of Contemporary Communication [M]. London:Amold, 2001: $87-88$

[2] Mood and Modality. Application of Multimodal Discourse Theory and Media Technology in Foreign Language Teaching $[\mathrm{J}]$. Foreign Language Teaching, 2009, (4).

[3] Ding-Fang Chuang Chi as modern foreign language teaching theory, practice and methods (revised edition) [M] Shanghai: Shanghai Foreign Language Education Press, 2009: 156--158.

[4] Gu Guanjie Chinese English Further Study [J].. Modern Foreign Languages. 2013 (03)
[5] (US) A · Bandura (Albert Bandura) with, Liu Ying translated thoughts and actions - social cognitive theory [M] East China Normal University Press, 2001.

[6] Liu Li silencing University English Classroom [6] [J]. Mudanjiang Teachers College (Philosophy and Social Sciences) 2009 (02).

[7] $\mathrm{Hu}$ Wen. Multimodal Discourse Analysis in English Teaching [J]. Shandong University of Technology (Social Science Edition) 2011 (03).

[8] Zhang Ke. New Media Age Multimodal Discourse Analysis Theory in College English Teaching [J]. Mudanjiang College of Education. 2013 (02).

[9] Huangyuan Zhen. Students learn language skills must change the way [J]. English. 2015 (11). 